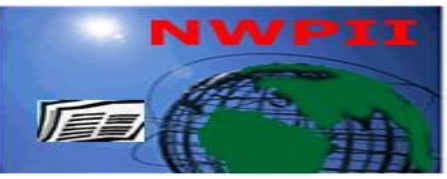

American Journal of

Biomedical Sciences

ISSN: 1937-9080

nwpii.com/ajbms

\title{
Intestinal Parasitic Infection and Candidiasis among Pregnant Women Attending Antenatal Clinic in Ilie, Southwest, Nigeria
}

\section{Muoneke Peter Declan ${ }^{1}$ PhD, Sanusi Tawakalit Omotayo ${ }^{2}$ M.Sc, *Adefioye Olusegun Adelowo ${ }^{1}$ M.Sc}

\author{
${ }^{1}$ Department of Medical Microbiology and Parasitology, College of Health Sciences, Ladoke Akintola University of \\ Technology, P.M.B. 4400, Osogbo Nigeria. \\ ${ }^{2}$ Department of Community Medicine, College of Health Sciences, Ladoke Akintola University of Technology, P.M.B. \\ 4400, Osogbo, Nigeria. \\ "Corresponding Author \\ Mr. Adefioye Olusegun Adelowo \\ Department of Medical Microbiology and Parasitology, \\ Ladoke Akintola University of Technology, \\ Osogbo, Osun State, \\ Nigeria. \\ Email: oaadefioye@lautech.edu.ng
}

Received:29 July 2020; | Revised:18 August 2020; | Accepted:08 December 2020

\begin{abstract}
Intestinal parasitic infection is one of the major health issues and poses major public health problem in developing countries particularly in Sub -Saharan countries including Nigeria in particular. A cross sectional study of intestinal parasites and Candida albicans infections was undertaken among pregnant women attending antenatal clinic in Ilie in order to determine the prevalence and intensity of the infections. The intensity of infection was classified into light, moderate or high according to World Health Organisation (WHO) thresholds. A total of 172 pregnant women aged between 15 to 54 years were recruited for this study. Fresh stool and high vaginal swabs samples were collected and processed according to parasitological and mycological procedures. The overall prevalence of intestinal parasites in this study was $(32.6 \%)$ with four difference species of intestinal parasites namely, Entamoeba histolytica (15.7 \%), Hookworm (8.7 \%) Ascaris lumbricoides (6.4\%) and Trichuris trichiura (1.7\%). In all, Candida albicans had the highest prevalence of $22.7 \%$. C. albicans/E. histolytica co-infection was the highest prevalence $(9.3 \%)$ while the least co-infection was $C$. albicans/A. lumbricoides (4.1\%). Age group 15-24 years had the highest prevalence $(58.1 \%)$ and the least was age group 35-44 years $(21.1 \%)$. There was no statistical significance between the age group and the infection $(\mathrm{P}=0.274)$. Most of the pregnant women had intestinal parasites in secondgravidae $(46.4 \%)$ and in 1 st trimester of gestation period $(46.4 \%)(\mathrm{P}=0.371)$, while Candida albicans was in secondgravidae $(48.7 \%)$ and in 3rd trimester of gestation period $(46.2 \%)(\mathrm{P}=0.629)$. Out of the 39 $(22.7 \%)$ pregnant women who were positive for Candida albicans, $32(82.1 \%)$ were co-infected with any intestinal parasites and the difference was not statistically significant $(\mathrm{P}=0.152)$. Therefore all pregnant women should undergo a routine examination for intestinal parasites and Candida albicans during antenatal visit. Health education should be introduced in order to highlight the principles of basic personal hygiene.
\end{abstract}


Keywords: Prevalence, Intensity, Intestinal parasitic infection, Candida albicans, Pregnant women

\section{Introduction}

Intestinal parasitic infections (IPI) cause a tremendous burden of disease in both the tropics and subtropics as well as in more temperate climates ${ }^{[1]}$. It is a major concern, mostly in developing countries, particularly in sub-Saharan Africa ${ }^{[2]}$. Climate is an important determinant of transmission of parasitic infections, with adequate moisture and warm temperature essential for larval development in the soil [3]. Women of reproductive age are among the people with clinical disease due to intestinal parasite infection in developing countries ${ }^{[4]}$. The routes of infections are ingestion of undercooked meat, drinking contaminated water, faecal-oral transmission and skin absorption [5]. Effect of soil transmitted helmithics infections lead to malnutrition, anaemia, and thrombocytopenia ${ }^{[6,7]}$, while the diseases caused by intestinal protozoans include: Amoebiasis, Giardiasis, Isosporiasis, Balantidiasis, Cryptosporidiosis, and Cyclosporiasis $[8,5]$. Intestinal protozoans also associated with diarrhoea and anaemia ${ }^{[5]}$.

Parasitic infections are common among pregnant women due to reduced body immunity and therefore can affect physiological systems of the body ${ }^{[9]}$. About tens millions of pregnant women worldwide are affected directly or indirectly by parasitic infection which eventually lead to a spectrum of adverse maternal and fetal/placental effects ${ }^{[9]}$. Parasitic infection could occur at any stage of the three trimesters during pregnancy, but during the first trimester, infection is more severe in fetal and placental associated infection than those occurring later in pregnancy. Ascaris lumbricoides coagulopathic properties can contribute to bleeding in pregnant women after birth ${ }^{[10]}$. Also, the infection becomes more severe in women who are pregnant for the first time (primigravidae) compared with other gravidae ${ }^{[11]}$.

Vulvovaginal candidiasis (VVC) is a female genital tract infection caused by the fungus candida species ${ }^{[12]}$. Candidiasis is a fungal infection caused by Candida and is an opportunistic infection ${ }^{[13]}$. In about $20-50 \%$ of healthy women, the presence of candida species in their lower genital tract is asymptomatic $[12,14]$. Candida infections are very common in pregnant women as a result of the increased levels of estrogens, glycogen, corticoids and other substrates reducing the vaginal defense mechanisms [15]. An estimated $75 \%$ of women experience at least one episode of vulvovaginal candidiasis during their lifetime, with $40 \%$ to $50 \%$ having two or more episodes ${ }^{[16]}$. Increased rate of vaginal colonization by candida have been attributed to a number of factors such as pregnancy, prolonged use of broad spectrum antibiotics and poor personal hygiene [12, 14]. Vulvovaginal candidiasis is also an important cause of morbidity in pregnancy which can cause abortion, candida chorioamnionitis, subsequent preterm delivery, emotional stress and suppression of immune system $[15,17]$. Intestinal parasitic infections and candidiasis are important public health problems in various countries especially in developing countries, but the severity may vary depending on the location and period of time. However, many works have been done in Nigeria as regards the prevalence of intestinal parasitic infections and candidiasis, but to my knowledge there is no information as regards it in Ilie.

The aim of this study was therefore designed to determine the prevalence of intestinal parasites and Candida albicans and co-infections among pregnant women attending antenatal clinics in Ilie, Southwest, Nigeria.

\section{Materials and Methods}

\subsection{Study Area}

The study area was Ilie, in Olorunda Local Government Area of Osun State, Nigeria. Ilie is about $20 \mathrm{~km}$ from Igbona, the headquarter of the Local Government. It is located in the rain forest zone between latitude $4^{0} 34^{1}$ and $4^{0} 36^{1} \mathrm{E}$ and Longitude $7^{\circ} 56^{1}$ and $7^{\circ} 58^{\mathrm{l}} \mathrm{N}$ with population of about 5,268 (National Population Commission, 2006). It is situated within the cocoa belt of Southwestern Nigeria. The area is rural and lack basic amenities such as good roads, standard hospitals and adequate facilities for refuse and sewage disposal. There is a big dam which serves as 
a source of water for bathing and other domestic activities. Members of the community are predominantly farmers though some engage in fishing and trading while some are civil servants. The community has one primary health center and three primary schools namely Community Primary School, Nawar-Ur-Deen Primary School and Saint James Primary School.

\subsection{Data Collection Procedures}

This was a cross-sectional descriptive study. Pregnant women attending the antenatal clinic for booking between 1st July, 2019 and $31^{\text {st }}$ June, 2020 were consecutively recruited into the study after obtaining their consent. A pre-tested structured questionnaire was administered by trained interviewer to obtain data on demographic information and obstetric history of the pregnant women, information obtained included age, gestational age and parity.

\subsection{Samples Collection}

The pregnant women were educated on how to collect the fresh stool samples that was passed in the morning into the clean plastic universal container that was provided for them. High vaginal swabs (HVS) was collected under aseptic condition with the aid of a speculum from the posterior fornix of the pregnant women by a trained and experience nurse by using sterile cotton swab stick. The two samples (faecal and HVS) were transported immediately to Medical Microbiology and Parasitology Laboratory, College of Health Science, Ladoke Akintola University of Technology, IsaleOsun, Osogbo campus, which is about $20 \mathrm{~km}$ from the study area within 4 hours of passage in order to ensure proper identification of hookworm eggs ${ }^{[18]}$.

\subsection{Preparation and Analysis Faecal Samples}

The appearance of each faecal sample was carefully examined macroscopically for colour, consistency, presence or absence of blood and mucus and presence or of adult worms. Direct saline/iodine preparation and formol-ether concentration methods were used to process the faecal samples and examined microscopically for the presence of parasite eggs using $\mathrm{x} 10$ and $\mathrm{x} 40$ objective lenses as recommended by WHO [18]. Based on WHO ${ }^{[18]}$ criterion, the intensity of intestinal helminths infections was determined using Kato-Katz template $(41.7 \mathrm{mg}$ ) technique by counting the number of eggs on single thick smear and was multiplied by 24 in order to quantify the number of eggs per gram (epg) of faeces ${ }^{[18]}$, but the intensity of intestinal protozoa could not be determined because threshold values are not available in World Health Organisation standard ${ }^{[18]}$.

\subsection{High Vaginal Swab Samples Analysis}

Sabouraud Dextrose Agar (SDA) culture media was prepared according to manufacturer instruction. The high vaginal swabs sample was inoculated by streaking onto Sabouraud dextrose agar plates and was incubated aerobically at $37^{\circ} \mathrm{C}$ for 24hours. The significant growth of yeast colony was observed morphologically. Grams' staining was performed on suspected yeast colony and Germ Tube Test (GTT) was also performed on it which is a confirmation test for $C$. albicans. Wet preparation sample was made by adding small amount of $0.5 \%$ of physiological saline into the swab stick and was mixed gently. A drop of mixed exudates was transferred onto a microscope slide and examined for budding yeast cell under the microscope at $\mathrm{x} 10$ and $x 40$ objective lenses ${ }^{[19]}$.

\subsection{Statistical Analysis}

Data obtained were analyzed using descriptive statistics while Chi-squared $(\chi 2)$ analysis was used to determine association between variables using SPSS version 24 statistical package. $\mathrm{P}<0.05$ was considered statistically significant.

\section{Results}

General and Obstetric Characteristics of Pregnant Women in Ilie is shown in Table 1. Out of the 172 pregnant women in the study area, age group 25-34 years (38.4\%) had the highest frequency, followed by age group 15-24 years $(25.0 \%)$ and the least was age group $45-54$ years $(14.5 \%)$. The mean age of the participants was $28.82 \pm 0.28$ year. Four species of intestinal parasites were identified namely, Entamoeba histolytica, Hookworm, Ascaris lumbricoides and Trichuris trichiura. E. histolytica was the most common parasite $(15.7 \%)$, followed by Hookworm (8.7 \%). In all, Candida albicans $(22.7 \%)$ had the 
highest frequency among the participants. $C$. albicans/E. histolytica co-infection was the highest prevalence $(9.3 \%)$ while the least co-infection was C. albicans/A. lumbricoides (4.1\%). Seventy nine $(45.9 \%)$ pregnant women were in the second trimester while fifty eight $(33.7 \%)$ were in their third trimester. Thirty five $(20.4 \%)$ of the participants were in the first trimester. Majority of the pregnant women in the study area are multigravidae $(39.5 \%)$, followed by primigravidae $(30.8 \%)$ while secondgravidae $(29.6 \%)$ was the least (Table 1).

Table 2 shows the prevalence of intestinal parasite and Candida albicans among pregnant women by age. The age of the pregnant women ranged from 15 to 54 years. The overall prevalence of intestinal parasites in this study was $(32.6 \%)$ with four difference species of intestinal parasites namely, Entamoeba histolytica (15.7\%), Hookworm (8.7\%) Ascaris lumbricoide (6.4\%) and Trichuris trichiura (1.7\%)..In all, Candida albicans had the highest prevalence of $22.7 \%$. C. albicans $/ E$. histolytica co-infection was the highest prevalence $(9.3 \%)$ while the least co-infection was $C$. albicans/A. lumbricoides (4.1\%). Age group 15 -24 years had the highest prevalence $(58.1 \%)$ and the least was age group 35-44 years $(21.1 \%)$. There was no statistical significant between the age group and the infections $(\mathrm{P}=0.274)$.

Prevalence and intensity of intestinal parasites among pregnant women is shown in Table 3. The intensity is calculated based on WHO guideline.
Intensity could not be calculated for E. histolytica parasite not listed by WHO. None of the pregnant women had heavy intensity of infection while $7 \%$ of those infected with Hookworm had light intensity and $1.7 \%$ had moderate intensity of infection. Ascaris lumbricoides had 2.3\% and 4.1\% light and moderate intensity respectively. $T$. trichiura had only light intensity of $1.7 \%$.

Table 4 shows the prevalence of intestinal parasites and Candida albicans by gestational age. Most of the pregnant women had intestinal parasites in secondgravidae $(46.4 \%)$ and in 1 st trimester of gestation period $(46.4 \%)(\mathrm{P}=0.371)$, while that Candida albicans is in secondgravidae (48.7\%) and in 3rd trimester of gestation period $(46.2 \%)(\mathrm{P}=$ 0.629).

The association between intestinal parasites and Candida albicans among pregnant women is shown in Table 5. Out of the 39 (22.7\%) pregnant women that were positive for Candida albicans, 32 $(82.1 \%)$ were co-infected with any intestinal parasites and the difference was not statistically significant $(\mathrm{p}>0.05)$. Women who had any intestinal parasites were almost equal with candida albicans $(\mathrm{OR}=1.617,95 \% \mathrm{CI}=0.493-2.507)$ as likely to be infected with Candida albicans as women with no worm infection. Also, pregnant women that have E. histolytica were two times less of Candida albicans (OR $=1.359,95 \% \mathrm{CI}=0.347$ 0.965). 
Table 1: General and Obstetric Characteristics of Pregnant Women in Ilie

\begin{tabular}{|l|l|l|}
\hline \multicolumn{1}{|c|}{ Variables } & Frequency N= 172 & \\
\hline Age Group (Years) & & \\
$15-24$ & 43 & 25.0 \\
$25-34$ & 66 & 38.4 \\
$35-44$ & 38 & 22.1 \\
$45-54$ & 25 & 14.5 \\
Mean age \pm SD & $28.82 \pm 0.28$ & \\
Parasites & 11 & \\
Ascaris lumbricoides & 15 & 6.4 \\
Hookworm & 3 & 8.7 \\
Trichuris trichiura & 27 & 1.7 \\
Entamoeba histolytica & 39 & 15.7 \\
Candida albicans & & 22.7 \\
Co-infection & 07 & \\
C. albicans + A. lumbricoides & 09 & 4.1 \\
C. albicans + Hookworm & 16 & 5.2 \\
C. albicans + E. histolytica & & 9.3 \\
Trimester & 35 & \\
First & 79 & 20.4 \\
Second & 58 & 45.9 \\
Third & & 33.7 \\
Gravidity & 53 & \\
Primigravidae & 51 & 30.8 \\
Secondgravidae & 68 & 29.6 \\
Multigravidae & & 39.5 \\
& & \\
\hline
\end{tabular}

Table 2: Prevalence of Intestinal Parasite and Candida albicans among pregnant women by age

\begin{tabular}{|c|c|c|c|c|c|c|}
\hline \multirow[t]{2}{*}{ Parasites } & \multicolumn{5}{|c|}{ Age Group (Years) } & \multirow{2}{*}{$\begin{array}{c}\text { P- } \\
\text { value }\end{array}$} \\
\hline & $\begin{array}{c}\mathrm{n}_{1}=43 \\
15-24 \\
(\%)\end{array}$ & $\begin{array}{c}n_{2}=66 \\
25-34(\%)\end{array}$ & $\begin{array}{c}\mathrm{n}_{3}=38 \\
35-44(\%)\end{array}$ & $\begin{array}{c}\mathrm{n}_{4}=25 \\
45-54(\%)\end{array}$ & $\begin{array}{c}\mathrm{N}=172 \\
\text { Total }(\%)\end{array}$ & \\
\hline $\begin{array}{l}\text { Ascaris lumbricoides } \\
\text { Hookworm } \\
\text { Trichuris trichiura } \\
\text { Entamoeba histolytica } \\
\quad \text { Total } \\
\text { Candida albicans } \\
\text { C. albicans + A.lumbricoides } \\
\text { C. albicans + E.histolytica } \\
\text { C. albicans + Hookworm }\end{array}$ & $\begin{array}{l}06(14.0) \\
04(9.3) \\
02(4.7) \\
13(30.2) \\
25(58.1) \\
15(34.9) \\
04(9.3) \\
09(20.9) \\
02(4.7)\end{array}$ & $\begin{array}{l}02(3.0) \\
07(10.6) \\
- \\
05(7.6) \\
14(21.2) \\
12(18.2) \\
02(3.0) \\
02(3.0) \\
05(7.6)\end{array}$ & $\begin{array}{l}03(7.9) \\
02(5.3) \\
- \\
03(7.9) \\
08(21.1) \\
08(21.1) \\
01(2.6) \\
01(2.6) \\
02(5.3)\end{array}$ & $\begin{array}{l}- \\
02(8.0) \\
01(4.0) \\
06(24.0) \\
09(36.0) \\
04(16.0) \\
- \\
04(16.0) \\
-\end{array}$ & $\begin{array}{l}11(6.4) \\
15(8.7) \\
03(1.7) \\
27(15.7) \\
56(32.6) \\
39(22.7) \\
07(4.1) \\
16(9.3) \\
09(5.2)\end{array}$ & 0.274 \\
\hline
\end{tabular}


Table 3: Prevalence and Intensity of Intestinal parasites among pregnant women

\begin{tabular}{|c|l|l|l|l|l|}
\hline Parasites & \multicolumn{1}{|c|}{$\begin{array}{c}\text { N=172 } \\
\text { No. } \\
\text { Positive (\%) }\end{array}$} & Negative & Light & Moderate & Heavy \\
\cline { 3 - 6 } & $11(6.4)$ & $161(93.6)$ & $04(2.3)$ & $07(4.1)$ & $0(0)$ \\
\hline A. lumbricoides & $15(8.7)$ & $157(91.3)$ & $12(7.0)$ & $03(1.7)$ & $0(0)$ \\
Hookworm & $03(1.7)$ & $169(98.3)$ & $03(1.7)$ & $0(0)$ & $0(0)$ \\
T. trichiura & $27(15.7)$ & $*$ & $*$ & $*$ & $*$ \\
E. histolytica & $56(32.6)$ & & & & \\
$\quad$ Total & & & & & \\
& & & & & \\
\hline
\end{tabular}

* Cyst of Entamoeba histolytica count could not be computed because threshold value is not available in WHO standard.

\section{A. lumbricoides}

Light - 1-4,999epg

Moderate-5,000-49,999epg

Heavy $\geq 50,000$ epg

\section{Hookworm}

Light- 1-1,999epg

Moderate-2,000-3,999epg

Heavy $\geq 4,000$ epg

\section{Trichuris trichiura}

Light - 1-999epg

Moderate 1,000-9,999epg

Heavy $\geq 10,000$ epg

Table 4: Prevalence of Intestinal Parasites and Candida albicans by Gestational age

\begin{tabular}{|c|c|c|c|c|c|c|c|c|}
\hline \multirow[t]{3}{*}{ Organism } & \multicolumn{4}{|c|}{ Gravidae } & \multicolumn{4}{|c|}{ Trimester } \\
\hline & Prima & Second & Multi & Total & $1 \mathrm{st}$ & $2^{\text {nd }}$ & $3^{\text {rd }}$ & Total \\
\hline & No. \% & No. \% & No. \% & No. \% & No. \% & No. \% & No. $\%$ & No. $\%$ \\
\hline $\begin{array}{c}\text { Parasites } \\
\text { A.lumbricoides } \\
\text { Hookworm } \\
\text { T, trichiura } \\
\text { E. histolytica } \\
\text { Total } \\
\text { Candida } \\
\text { albicans }\end{array}$ & $\begin{array}{l}02(18.2) \\
08(53.3) \\
01(33.3) \\
14(51.9) \\
25(44.6) \\
12(30.8)\end{array}$ & $\begin{array}{l}09(81.1) \\
04(26.7) \\
02(66.7) \\
11(40.7) \\
26(46.4) \\
19(48.7)\end{array}$ & $\begin{array}{c}0(0) \\
03(20.0) \\
0(0) \\
02(7.4) \\
05(8.9) \\
08(20.5)\end{array}$ & $\begin{array}{c}11(6.4) \\
15(8.7) \\
03(1.7) \\
27(15.7) \\
56(32.6) \\
39(22.7)\end{array}$ & $\begin{array}{c}05(45.5) \\
08(53.3) \\
0(0) \\
13(48.2) \\
26(46.4) \\
07(18.0)\end{array}$ & $\begin{array}{c}02(18.2) \\
01(6.7) \\
03(100) \\
07(25.9) \\
13(23.2) \\
14(35.9)\end{array}$ & $\begin{array}{c}04(36.4) \\
06(40.0) \\
0(0) \\
07(25.9) \\
17(30.4) \\
18(46.2)\end{array}$ & $\begin{array}{c}11(6.4) \\
15(8.7) \\
03(1.7) \\
27(15.7) \\
56(32.6) \\
39(22.7)\end{array}$ \\
\hline P-value & \multicolumn{4}{|c|}{0.371} & \multicolumn{4}{|c|}{0.629} \\
\hline
\end{tabular}

Table 5: Association between Intestinal parasites and Candida albicans among pregnant women

\begin{tabular}{|l|l|l|l|l|l|}
\hline \multirow{1}{*}{ Parasites } & \multicolumn{3}{|c|}{ Candida albicans } & \multirow{2}{*}{ P- value } \\
\cline { 2 - 4 } & $\begin{array}{c}\text { Absent (N= } \\
\mathbf{1 3 3})\end{array}$ & \multicolumn{1}{|c|}{ Present (N=39) } & $\begin{array}{c}\text { Odd } \\
\text { Ratio }\end{array}$ & $\begin{array}{c}\text { Confidence Interval } \\
\text { (95\%CI) }\end{array}$ & \\
\cline { 2 - 3 } & \multicolumn{1}{|c|}{ No. (\%) } & \multicolumn{1}{|c|}{ No) } & & & \\
\hline Any Int. parasites & $24(18.1)$ & $32(82.1)$ & 1.617 & $0.493-2.507$ & 0.152 \\
A. lumbricoides & $04(3.0)$ & $7(18.0)$ & 1.500 & $0.106-21.312$ & 0.092 \\
Hookworm & $06(4.5)$ & $9(23.1)$ & 0.261 & $0.026-2.580$ & 0.765 \\
T, trichiura & $03(2.3)$ & $0(0)$ & 0.750 & $0.032-17.506$ & 0.250 \\
E. histolytica & $11(8.3)$ & $16(41.0)$ & 1.359 & $0.347-0.965$ & 0.163 \\
& & & & & \\
\hline
\end{tabular}




\section{Discussion and Conclusion}

This study was undertaken to determine the prevalence of intestinal parasites and Candida albicans among pregnant women attending antenatal clinics in Ilie, southwestern, Nigeria. Intestinal parasite is one of the most prevalent infectious diseases in the tropical and subtropical areas of the world; also it is a medical and public health problem in sub-Saharan countries including Nigeria in particular. Pregnant women are one of the most vulnerable groups for this infection due to their immune suppression during their pregnancy. Out of the 172 pregnant women in the study area, overall prevalence of intestinal parasites was $32.6 \%$ with four different species which include; Ascaris lumbricoides, Hookworm, Trichuris trichiura and Entamoeba histolytica. However, E. histolytica $(15.7 \%)$ recorded the highest prevalence, followed by Hookworm $(8.7 \%)$ and T. Trichiura $(1.7 \%)$ was the least prevalence. The prevalence of Candida albicans among pregnant women was $(22.7 \%)$. The occurrence of these parasites among pregnant women have been reported in some parts of Nigeria and have been attributed to faecal pollution of soil and domestic water supply around homes due to poor sanitation and improper sewage disposal. ${ }^{[20,21,}$ 23]. The hyperendemicity of soil-transmitted helminths, especially among children pose many maternal women to high risk of infection because of their close relationship with children. In this study, an overall prevalence of intestinal parasites (32.6\%) reported was significantly higher than those findings from the studies in Congo by Mordi et. al., ${ }^{[21]}(9 \%)$ and in Nigeria by Rodríguez-Morales et al., ${ }^{[23]}(0.7 \%)$ and Omudu, ${ }^{[22]}(1.8 \%)$, and also lower compared to that found in other developing countries such as Ecuador (93\%), Venezuela (74\%) and Indonesia $(70 \%){ }^{[23,24,25]}$. The prevalence rate of $32.6 \%$ was almost similar to the works conducted in Ethiopia by Bolka and Gebremed, [26] with prevalence rate of $38.7 \%$.

Prevalence of E. histolytica (15.7\%) which is intestinal protozoan found in this study was higher than any species of intestinal helminths. This finding is similar to the report in Papua New Guinea that intestinal protozoan were more prevalent than intestinal helminths among pregnant women ${ }^{[25,27] .}$
This prevalence was low compared to other studies conducted in Nigeria by Obadiah ${ }^{[28]}(37.9 \%)$ and Ibrahim ${ }^{[29]}(45 \%)$. The high prevalent of $E$. histolytica $(15.7 \%)$ in this study could be as a result contamination of food, vegetables and drinks by home flies which are mechanical transmitter for these parasites ${ }^{[25]}$. The predominant intestinal helminths in this study were Hookworm (8.7\%), followed by Ascaris lumbricoides (6.4\%). Higher prevalence of Hookworm is almost similar to the work of Luoba et. al., [30] who reported the prevalence rate of $11.2 \%$. This value is low when compared to the work of Brooker et. al., ${ }^{[31]}$ who reported prevalence of $74.9 \%$ among pregnant women attending antenatal clinic at Kilifi Kenya and Egwuyenga et. al., ${ }^{[32]}$ (22.5\%) at Eku in Delta State of Nigeria. Brooker et. al., ${ }^{[31]}$ also reported $56.6 \%$ at Ukerewe Island Tanzania, $44.5 \%$ in Entebbe Uganda, and $8.1 \%$ in Venezuela pregnant women. It is well-established that human hookworm infection results in intestinal blood loss which, in turn, can contribute to low haemoglobin levels (Brooker et. al., ${ }^{[31]}$. Hookworm sustains its life by blood sucking, a process that ruptures the host capillaries and arterioles followed by the release of a battery of pharmacologically active polypeptides which induces intestinal blood loss. Adult $N$. americanus worm sucks approximately $0.05 \mathrm{ml} / \mathrm{dl}$ of blood and $A$. duodenale approximately $0.25 \mathrm{ml} / \mathrm{dl}$ of blood per day ${ }^{[33]}$.

The prevalence of $6.5 \%$ for Ascaris lumbricoides in this study was however low compared to the work conducted in Indonesia by Widjana and Sutisna ${ }^{[34]}(73.7 \%)$. Prevalence of Trichuris trichiura (1.7\%) was low compared to Luoba et. al ${ }^{[30]}$ who reported $4.6 \%$ in Kenya, and $1.7 \%$ in Nigeria by Alakija et. al., ${ }^{[35]}$. It is however higher than $0.9 \%$ reported among pregnant women in Ghana by Baidoo et. al., ${ }^{[36]}$. The possible differences might be due to the geographical difference and the habit of walking barefoot which could favours the transmission of hookworm. Poor sanitary disposal of human faeces and indiscriminate defaecation are the principal factors in the aetiology of many intestinal helminths infections, ${ }^{21]}$.

Transmission occurs through poor sanitary habits of indiscriminate defaecation. Infections 
usually occur through ingestion of ova from contaminated hands, food or drinks ${ }^{[21]}$.

The prevalence of intestinal parasites infection was highest among the age group15-24 years $(58.1 \%)$, followed by age group $45-54$ years $(36.0 \%)$, and the least was age group 35-44 years $(21.1 \%)$. The prevalence rate was decreasing with increasing age group except age group 45-54 years, this could possibly due to change in attitude, habits and more awareness regarding personal hygiene among the subjects. However, this finding is not similar to the report in Ghana by Yatich et. al. [37] and in Nigeria by Akinbo et. al. ${ }^{[38]}$ that younger age among the pregnant women is associated with intestinal parasitic infections. The finding from this study is in tandem with the report of Phuanukoonnon et. al. ${ }^{25]}$ in Papua New Guinea that age was not associated with intestinal parasitic infections among pregnant women and the difference was not statistically significant $(\mathrm{P}=0.274)$. Out of the $39(22.7 \%)$ pregnant women that were positive for Candida albicans, 32 (82.1\%) were coinfected with any intestinal parasites and the difference was not statistically significant $(p>0.05)$. There is however, no report on how intestinal parasite infection affects candida infection.

This study reveals the prevalence of Candida albicans among pregnant women to be $22.7 \%$. This prevalence rate is almost in tandem with the reports conducted in Nigeria and Accra by DonbrayeEmmanuel et. al., ${ }^{[12]}$ (24.4\%); Akinbami et. al., [39] (25\%); Anorlu et. al., ${ }^{[40]}$ (26\%); Okonkwo and Umeanaeto, ${ }^{[41]}$ (30\%); Olowe et. al., ${ }^{[42]}$ (36.0\%); Apea-Kubi et. al., ${ }^{[43]}$ (34.2\%) and Guzel et. al., ${ }^{[44]}$ $(37.4 \%)$. The differences in the prevalence could be due to geographical, socioeconomical and environmental factors such as differences in sexual practice, hygiene and nutrition ${ }^{[45]}$. Increased secretion of reproductive hormones both progesterones and estrogens during pregnancy favours the formation of infection. The high prevalence of vaginal candidiasis may lead to pregnancy complications like abortions, premature birth, low birth weight and other morbidities.

The prevalence of Candida albicans infection was highest among the age group15-24 years (34.9), followed by $35-44$ years $(21.1 \%)$, and the least was age group $45-54$ years $(16.0 \%)$ which is almost similar to the study reported by Akinbami et. al., ${ }^{[39]}$.
The younger age group women are sexually active and also have low vaginal defense mechanisms against Candida species and most always have the habit of using contraceptives especially the emergency pills to prevent pregnancy [46]. This study revealed the high prevalent Candida albicans infection among pregnant women in secondgravidae $(48.7 \%)$ and in 3 rd trimester of gestation period $(46.2 \%)$, followed by primigravidae $(30.8 \%)$ and 2nd trimester $(35.9 \%)$. The finding is not in agreement with Akinbami et. al., ${ }^{[39]}$ who reported that high prevalence $(54.3 \%)$ of Candida albicans infection was observed in 2nd trimester, followed by $25.7 \%$ in 1 st trimester and $20 \%$ in 3 rd trimester. This study is limited in several aspects as we did not cover other communities within the local government area due to lack of financial resources. This study also could not be able to assess the relationship between intestinal parasite/candida infections and the potential risk factors which include occupation, educational status, water source, and type of toilet facility. A future study needs to be done in order to include other communities in the study area, so that more subjects would be recruited. However, there is need for government to establish health programme for the control of intestinal parasites and Candida albicans among pregnant women. Therefore all pregnant women should undergo a routine examination for intestinal parasites and Candida albicans during antenatal visit and treat the infected women accordingly. Health education should be enhanced in both rural and urban setups in order to highlight the principles of basic personal hygiene such as importance of toilet use, washing of hand always, wearing of shoe and adhere to personal hygiene. Strict antenatal routine checks up should be conducted among all the pregnant women at regular interval of time for early diagnosis of the infections.

\section{References}

1 Center for Disease Control.Centers for Disease Control and Prevention Fact Sheet-Kenya 2015. CDC, 2015; Atlanta.

2 Harhay MO, Horton J, Olliaro PL. Epidemiology and control of human gastrointestinal parasites in children. Expert 
Rev Anti Infect Ther 2010; 8(2): 219-234 DOI: 10.1586/eri.09.119

3 Brooker S,Michael E.The potential of geographical information systems and remote sensing in the epidemiology and control of human helminth infections. Advances in Parasitology, 2000; 47: 245-288 DOI:10.1016/S0065-308X(00)47011-9

4 Quihui L, Valencia ME, Crompton DW, Phillips S, Hagan P, Morales G, DiazCamacho SP. Role of the employment status and education of mothers in the prevalence of intestinal parasitic infections in Mexican rural schoolchildren. BMC Public Health 2006; 6: 225 DOI: $10.1186 / 1471-2458-6-225$

5 Alzain BF, Sharma PN. Haemoglobin Levels and Protozoan Parasitic Infection in School Children of Udaipur City (India). Journal of Al Azhar University-Gaza (Natural Science), 2006; 8: 35-40.

6 Fuseini G,Edoh D,Kalifa BG,Hamid A, Knight D. Parasitic Infections and anaemia during pregnancy in the Kassena-Nankana District of Northern Ghana. Global Journal of Gynecology and Obstetrics, 2010; 1 (1): 6165.

7 Pullan RL, Smith JL, Jasrasaria R, Brooker S.J. Global numbers of infection and disease burden of soil transmitted helminth infections in 2010. Parasites and Vectors, 2014; 21 (7): 37

DOI:

http:///www.parasitesandvectors.com/content/7 $11 / 37$

8 Davis AN, Haque R, Petri WA, Jr. Update on protozoan parasites of the intestine. Curr Opin Gastroenterol 2002; 18(1): 10-14 [PMID: $17031224 \quad$ DOI: $10.1097 / 00001574-$ 200201000-00003]

9 Derso A, Nibret E, Munshea A. Prevalence of intestinal parasitic infections and associated risk factors among pregnant women attending antenatal care center at Felege Hiwot Referral Hospital, northwest Ethiopia. BMC Infect Dis 2016; 16(1): 530 DOI: 10.1186/s12879-0161859-6

10 Zapardiel I, Peiretti M, Godoy-Tundidor S. Concurrent puerperal hysterectomy with Ascaris lumbricoides infestation: coincidence or consequence? Am J Obstet Gynecol 2010; 202(4): e4-5 DOI: 10.1016/j.ajog.2010.01.026

11 Muhangi L, Woodburn P, Omara M, Omoding N, Kizito D, Mpairwe H, Nabulime J, Ameke C, Morison LA, Elliott AM. Associations between mild-to-moderate anaemia in pregnancy and helminth, malaria and HIV infection in Entebbe, Uganda. Trans $\boldsymbol{R}$ Soc Trop Med Hyg 2007; 101(9): 899-907 DOI: 10.1016/j.trstmh.2007.03.017

12 Donbraye-Emmanuel, O, Donbraye E, Okonko I, Alli J, Ojezele M, Nwanze J. Detection and prevalence of Candida among pregnant women in Ibadan, Nigeria. World Applied Science Journal, 2010; 10(9): 986-991.

13 Akinbami NA, Babalola OG, Shittu OM, Tijani MA. Adekola AS. Detection and Epidemiology of Vulvovaginal Candidiasis among Asymptomatic Pregnant Women Attending a Tertiary Hospital in Ogbomoso, Nigeria. Int. J. Biomed. Res., 2015; 6(07): 1823 [DOI: $\underline{10.7439 / \mathrm{ijbr}]}$

14 Alli JAO, Okonko IO, Odu NN, Kolade AF, Nwanze JC. Detection and prevalence of Candida isolates among patients in Ibadan, Southwestern Nigeria. Journal of Microbiology and Biotechnology Research, 2011; 1(3): 176-184.

15 Sobel JD. Vaginitis. N Engl J Med 1997; 337(26): 1896-1903 [PMID: 9407158 DOI: 10.1056/NEJM199712253372607]

16 Sobel JD .Vulvovaginal candidosis.Lancet, 2007; 369(9577): 1961-1971. [DOI: 10.1016/S0140-6736(07)60917-9].

17 Singh SI . Treatment of Vulvovaginal Candidiasis. Clin. J. Rev. CPJ/RPC, 2003; 136(9): 26-30.

18 World Health Organisation. Soil-transmitted helminths infections. Geneva. 2016.

19 Cheesbrough M. District Laboratory Practice in Tropical Countries.2nd Edition. Part2.Cambridge University Press, London, 2009; pp. 195-206.

20 Obiamiwe BA, Nmorsi P. Human gastrointestinal parasites in Bendel State, Nigeria. Angew Parasitol 1991; 32(3): 177-183 [PMID: 1928804]

21 Mordi RM,Ngwodo POA. A study of blood and gastro-intestinal parasites in Edo State. 
African Journal of Biotechnology, 2007; 6 (19): 2201-2207.

22 Omudu EA. Sustainable human health and excreta management: a parasitological perspective on sanitation and epidemiology of excreta-related parasitic infections. International Journal of Environmental Issues, 2003; 1(2): 97 - 111.

23 Rodriguez-Morales AJ, Barbella RA, Case C, Arria M, Ravelo M, Perez H, Urdaneta O, Gervasio G, Rubio N, Maldonado A, Aguilera Y, Viloria A, Blanco JJ, Colina M, Hernandez E, Araujo E, Cabaniel G, Benitez J, Rifakis P. Intestinal parasitic infections among pregnant women in Venezuela. Infect Dis Obstet Gynecol 2006; 2006: 23125 DOI: 10.1155/IDOG/2006/23125

24 Meloni D, Mantini C, Goustille J, Desoubeaux G, Maakaroun-Vermesse Z, Chandenier J, Gantois N, Duboucher C, Fiori PL, Dei-Cas E, Duong TH, Viscogliosi E. Molecular identification of Pentatrichomonas hominis in two patients with gastrointestinal symptoms. $\boldsymbol{J}$ Clin Pathol 2011; 64(10): 933-935 [PMID: 21551465 DOI: $10.1136 /$ jcp.2011.089326]

25 Phuanukoonnon S, Michael A, Kirarock WS, Pomat WS, Van Den Biggelaar AHJ. Intestinal parasitic infections and anaemia among pregnant women in the highlands of Papua New Guinea. Papua New Guinea Medical Journal, 2013; 56 (3-4):119-125.

26 Bolka A, Gebremedhin S. Prevalence of intestinal parasitic infection and its association with anemia among pregnant women in Wondo Genet district, Southern Ethiopia: a cross-sectional study. BMC Infectious Diseases, 2019; 19: 483. [DOI: 10.21203/rs.2.9532/v2].

27 Asma I, Johari S, Sim BL, Lim YA. How common is intestinal parasitism in HIVinfected patients in Malaysia? Trop Biomed 2011; 28(2): 400-410 [PMID: 22041762]

28 Obadiah HI . Review of the survey of Entamoeba histolytica in Children a Brief Focus on Nigeria Situation. Journal of Physiology and Pharmacology Advances, 2012; 2(3): 150-157.

29 Ibrahim S. Transmission of amoebiasis at some selected areas of Kano metropolis, Kano State,
Nigeria: The role of human faeces used as manure. Bayero Journal of Pure and Applied Sciences, 2008; 1(1): 3235 [DOI: 10.4314/bajopas.v1i1.57509].

30 Luoba AI, Wenzel Geissler P, Estambale B, Ouma JH, Alusala D, Ayah R, Mwaniki D, Magnussen P, Friis H. Earth-eating and reinfection with intestinal helminths among pregnant and lactating women in western Kenya. Trop Med Int Health 2005; 10(3): 220-227 [PMID: 15730505 DOI: 10.1111/j.1365-3156.2004.01380.x]

31 Brooker S, Hotez PJ, Bundy DA. Hookwormrelated anaemia among pregnant women: a systematic review. PLoS Negl Trop Dis 2008; 2(9): e291

DOI: 10.1371/journal.pntd.0000291

32 Egwuyenga OADP, Nmorsi QPG. Studies on intestinal helminthes infection in Eku, Delta State, Nigeria. Nigerian Society of Parasitology, 2004; 20: 24.

33 Huddle JM, Gibson RS, Cullinan TR. The impact of malarial infection and diet on the anaemia status of rural pregnant Malawian women. Eur J Clin Nutr 1999; 53(10): 792801 DOI: $10.1038 /$ sj.ejcn. 1600851

34 Widjana DP, Sutisna P. Prevalence of soiltransmitted helminth infections in the rural population of Bali, Indonesia. Southeast Asian J Trop Med Public Health 2000; 31(3): 454459 [PMID: 11289000]

35 Alakija W. Prevalence of intestinal parasitic disease agents in stools of people in a rural area of Nigeria. Ann Trop Med Parasitol 1986; 80(5): 545-547 [PMID: 3632103 DOI: 10.1080/00034983.1986.11812063]

36 Baidoo SE, Tay SCK, Abruguah HH. Intestinal infection and anaemia during pregnancy. A community Based study in Ghana. African Journal of Microbiology Research, 2010; 4(16): 1713-1718.

37 Yatich NJ, Jiang Y, Tsiri A, Archer T, Julian C, Rayner JK, Stiles WO, Ellis EF, Jonathan HW, Pauline E J. Malaria and helminth co infection among pregnant women in Ghana: Prevalence and Risk Factors. American Journal of Tropical Medicine and Hygiene, 2009; 80 (6): 896-901. 
38 Akinbo FO, Okaka CE, and Omoregie R. Prevalence of intestinal parasitic infections among HIV patients in Benin City. Nigeria. Libyan Journal of Medicine, 2010; 5: 5506.

39 Akinbami AN,Babalola GO, Shittu MO, Tijani AM, Adekola SA. Detection and Epidemiology of Vulvovaginal Candidiasis among Asymptomatic Pregnant Women Attending a Tertiary Hospital in Ogbomoso, Nigeria. International Journal of Biomedical Research, 2015; 6(07): 518-523 [DOI: 10.7439/ijbr.v6i7.2242]

40 Anorlu R, Imosemi D, Odunukwe N, Abudu O, Otuonye M. Prevalence of HIV among women with vaginal discharge in a gynecological clinic. J Natl Med Assoc 2004; 96(3): 367-371 [PMID: 15040519 PMCID: PMC2594863]

41 Okonkwo NJ, Umeanaeto PU. Prevalence of vaginal candidiasis among pregnant women in Nnewi Town of Anambra State, Nigeria. African Research Review, 2010; 4(4): 539-548.

42 Olowe OA, Makanjuola OB, Olowe R, Adekanle DA. Prevalence of vulvovaginal candidiasis, trichomoniasis and bacterial vaginosis among pregnant women receiving antenatal care in Southwestern Nigeria. Eur $\boldsymbol{J}$ Microbiol Immunol (Bp) 2014; 4(4): 193-197 DOI: 10.1556/EUJMI-D-14-00027
43 Apea-Kubi KA, Sakyi B, Yamaguchi S, OforiAdjei D. Bacterial vaginosis, Candida albicans and Trichomonas vaginalis infection in antenatal and gynaecological patients in Ghana. Tropical Journal of Obstetrics and Gynaecology, 2005; 22(2): $108-112$ [DOI:10.4314/tjog.v22i2.14506]

44 Guzel AB, Ilkit M, Burgut R, Urunsak IF, Ozgunen FT. An evaluation of risk factors in pregnant women with Candida vaginitis and the diagnostic value of simultaneous vaginal and rectal sampling. Mycopathologia 2011; 172(1): 25-36 DOI: 10.1007/s11046-0119392-Z

45 Busetti M, D'Agaro P, Campello C. Group B streptococcus prevalence in pregnant women from North-Eastern Italy: advantages of a screening strategy based on direct plating plus broth enrichment. J Clin Pathol 2007; 60(10): 1140-1143 DOI: $10.1136 /$ jcp.2006.043489

46 Kent H. Epidemiology of Vaginitis. American J. Obs. Gynec., 1991; 165(4): 1168-1176. [DOI: 10.1016/S0002-9378 (12)90722-X]. 